\title{
A Kinetic Study of Drying of Teos-Derived Gels Under Nearly
}

\section{Isothermal Conditions}

\author{
Dario A. Donatti*, Alberto Ibañez Ruiz, Dimas R. Vollet \\ Departamento de Física, \\ IGCE/UNESP - Campus de Rio Claro \\ Rua Dez, 2527, 13500-230 Rio Claro - SP, Brazil; \\ e-mail:dario@laplace.igce.unesp.br
}

Received: December 15, 1998

\begin{abstract}
The drying of wet Tetraethoxysilane-derived gels was studied by means of thermogravimetric analysis as a function of the time, from the instant when the samples were placed into a pre-heated oven, kept at 70,83 and $100{ }^{\circ} \mathrm{C}$. The precursor sol of the gel was obtained by sono-hydrolysis of the Tetraethoxysilane under acid condition and the final [Water]/[Tetraethoxysilane] molar ratio was adjusted to 30 . The wet gels were cylindrical $(2.5 \mathrm{~cm}$ height and $1.2 \mathrm{~cm}$ diameter) after 30 days of aging at $30^{\circ} \mathrm{C}$ in a hermetically sealed container. The changes in volume and weight during drying are compatible with a mechanism controlled by evaporation from a flat liquid-vapour interface at the surface of the body and contraction of the gel by capillary forces, together with structural changes induced by polycondensation, which partially account for the irreversible shrinkage of the gel. The employed thermogravimetric method does not permit to unequivocally follow the small and slow final loss of weight associated to the falling rate periods.
\end{abstract}

Keywords: TEOS-derived gels, drying, kinetics

\section{Introduction}

The sol-gel process has become an useful tool in preparing finely divided powders or monoliths of glasses and glass-ceramics from hydrolysis of alcoxides ${ }^{1,2}$. This process involves hydrolysis and polycondensation reactions, gelation, aging and drying of the wet gels. The wet gel structure frequently exhibits a volume fractal feature ${ }^{3}$ consisting of a continuous solid network incorporating a continuous liquid phase, which can occupy 95 to $98 \%$ of the volume $^{4}$. Drying is the most critical step of the sol-gel processing if monoliths or the textural properties of the wet gels are intended to be preserved ${ }^{1,5-7}$. Supercritical drying (aerogels), freeze drying (criogels) ${ }^{4}$ and evaporation drying (xerogels $)^{1}$ are usual methods for dried gels production.

The usual drying process for xerogels exhibits three distinct stages: the constant rate period (CRP), the first falling rate period and the second falling rate period ${ }^{6}$. The constant rate period, in which the greatest changes in volume, weight and structure occur, is controlled by evaporation from the surface of the body and ends when shrinkage ceases $^{1,6}$. The rate of evaporation per unit area of the drying surface remains constant while the solid network collapses into the liquid, as a result of the compressive stress imposed by the tensile stress (capillary forces) of the liquid, and the liquid/vapor meniscus is kept at the drying surface ${ }^{6}$. The first falling rate period starts when the network becomes strong enough to resist further shrinkage and the radius of meniscus reduces enough to enter the pore, which begins to empty. This stage is controlled by flow through small pores and liquid layers over the pore surface and only small changes in weight and volume are observed ${ }^{1}$. In the second falling rate period, the liquid pathway to the surface becomes discontinuous and a very small loss of weight follows, until the equilibrium, by evaporation within the pores and diffusion of the vapor to the surface ${ }^{1}$.

It has been pointed that most alkoxide-derived gels may not exhibit a CRP which could be attributed to the mixture of water and alcohol which composes the liquid phase of the gel ${ }^{6}$. Kawaguchi et $a l .{ }^{8}$ found the evaporation rate to be initially constant for large pore silica gel, meanwhile Hench and Wilson ${ }^{1}$ did not find a constant rate of loss of weight 
during drying alkoxide-derived gels, even when normalized to the surface area.

In this work we study the kinetics of drying of Tetraethoxysilane (TEOS)-derived gels as a function of temperature by means of thermogravimetric analysis, from the instant when the sample is placed into the pre-heated oven of the thermogravimetric analyser, which kept at a constant temperature.

\section{Experimental Procedure}

Tetraethoxysilane (TEOS) (Wacker 97\%), distilled and deionized water and $\mathrm{HCl}$ (Merck 37\%) were used to prepare a two-phase TEOS-water-HCl mixture in a molar ratio 1:6.75:0.005, respectively. The mixture $(\sim 100 \mathrm{~mL})$ was submitted to hydrolysis for 15 min under ultrasonic stimulation using a $20 \mathrm{kHz}-600 \mathrm{~W}$ apparatus (Sonics \& Material VC600) with a $13 \mathrm{~mm}$ diameter titanium transducer, driven by an electrostrictive device. Under these conditions, hydrolysis takes place with its maximum rate at about $5 \mathrm{~min}$ of ultrasound stimulation ${ }^{9,10}$. Next, water was added to the solution, until the molar ratio [water]/[TEOS] $=30$, and the ultrasound was continued for 5 min for complete homogenization. High water contents are desired in order to favor the production of monoliths after drying the so derivedgel $^{11}$.

Gelling of the sols and aging of the wet gels were carried out in hermetically closed cylindrical polypropylene containers kept at $30{ }^{\circ} \mathrm{C}$. Gelling occurred within 1 day and aging was extended for 30 days. The cylindrical samples of the wet gels were about $2.5 \mathrm{~cm}$ height and $1.2 \mathrm{~cm}$ diameter, after a minor syneresis. Assuming complete hydrolysis and polycondensation reactions, and no evaporation of alcohol during preparation and aging of the gel, the composition of the liquid phase of the gel would be approximately $25 \%$ weight alcohol.

The thermogravimetric analysis was carried out in a BP-3000 equipment (BP-Engenharia/Brazil) controlled by a Pentium CPU through an $\mathrm{A} / \mathrm{D}$ heating rate controller board. The samples, innitially at $30{ }^{\circ} \mathrm{C}$, were placed, each one at once, into the pre-heated oven of the thermogravimetric analyser at the temperatures TOVEN $_{\text {OV }}=70,83$ and $100{ }^{\circ} \mathrm{C}$, respectively. The initial time was defined as the instant in which the samples were placed into the furnace. The sample temperature was measured by a Chromel/Alumel thermocouple placed just below the sample, in contact with a thin Ni-crucible which held the sample. The output data of the weight loss were obtained as a function of both the sample temperature (T) and the time $(\mathrm{t})$ of heat treatment. An atmospheric air flux was driven through the tube of the oven to avoid vapor condensation. The same conditions of the flow rate and moisture content were maintained for all samples studied.

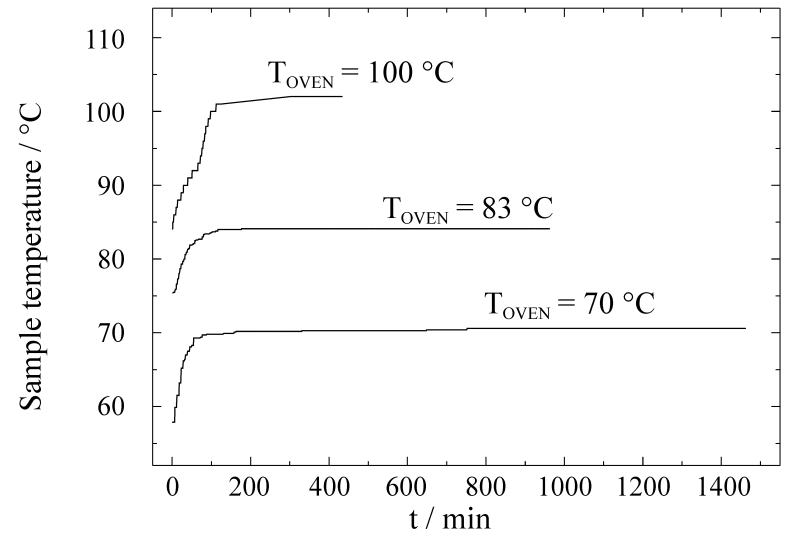

Figure 1. Sample temperature response as a function of the time, from the instant when the samples were placed into the pre-heated oven at the indicated temperature TOVEN

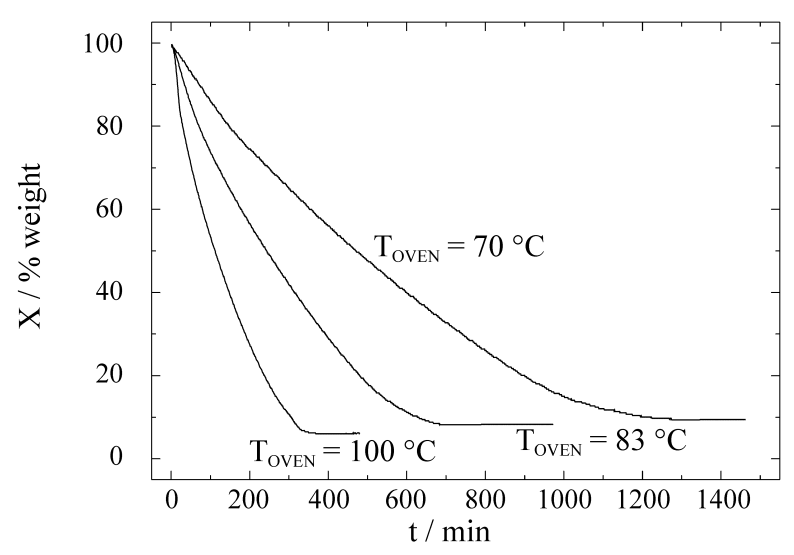

Figure 2. Sample weight loss as a function of the time, from the instant when the samples were placed into the pre-heated oven at the indicated temperature TOVEN

\section{Results and Discussion}

Figure 1 shows the temperature response of the samples as a function of the time $(\mathrm{t})$ from the instant when the samples were placed into the oven of the thermogravimetric analyser, pre-heated at TOVEN $=70,83$ and $100{ }^{\circ} \mathrm{C}$. Figure 2 shows the weight loss of the initially wet gels through the plots of the instantaneous percentage of the sample weight $(\mathrm{X})$, with respect to the initial wet gel weight, as a function of the time $(\mathrm{t})$ of heat treatment. Figure 3 shows the sample temperature response under the condition $T_{\text {OVEN }}$ as a function of the instantaneous sample weight percentage $(\mathrm{X})$.

The temperature of the sample at $\mathrm{T}_{\text {OVEN }}=100{ }^{\circ} \mathrm{C}$ showed a tendency to keep constant around $90{ }^{\circ} \mathrm{C}$ at the beginning of the drying process (Figs. 1 and 3), in opposition to the heat treatment, because the sample temperature should be the boiling point of the alcohol-water mixture of the liquid phase at this stage. 


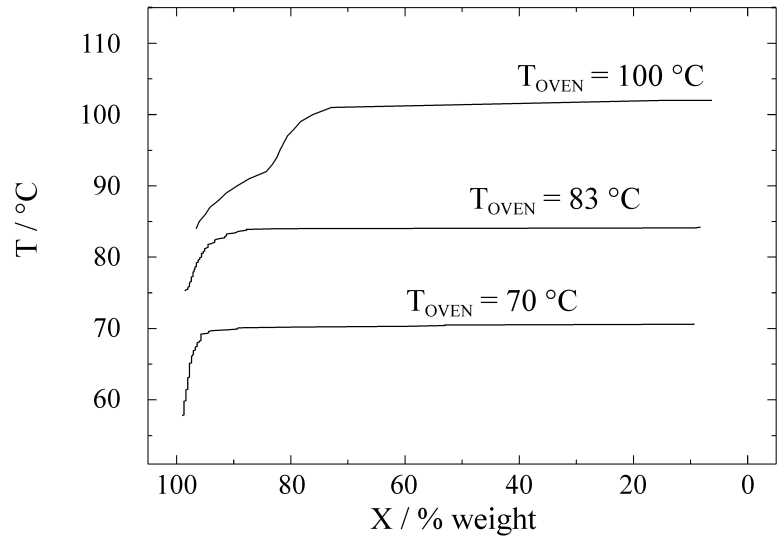

Figure 3. Sample temperature response as a function of the instantaneous weight of the sample placed into the oven at the temperature TOVEN.

The remaining sample weight $\left(\mathrm{X}_{\mathrm{eq}}\right)$, as inferred from the asymptotic limit of $\mathrm{X}$ for high drying time in Fig. 2, diminishes with the temperature. $\mathrm{X}_{\mathrm{eq}}$ was found to be 9.4 , 8.3 and $6.2 \%$ for the samples treated at $T_{\text {OVEN }}=70,83$ and $100{ }^{\circ} \mathrm{C}$, respectively. The minimum theoretical value for $\mathrm{X}_{\mathrm{eq}}$ was estimated for these samples as being $9.0 \%$, under the assumption that the remaining weight after drying is composed just by silica $\left(\mathrm{SiO}_{2}\right)$, which would be yielded in the gel preparation if it had undergone a 100\% hydrolysis and polycondensation reaction. This value agrees reasonably well with the experimental value of $9.4 \%$ for TOVEN $=70{ }^{\circ} \mathrm{C}$, fairly well with $8.3 \%$ for TOVEN $=83{ }^{\circ} \mathrm{C}$, but does not agree very well with $6.2 \%$ for $\mathrm{T}_{\text {OVEN }}=100{ }^{\circ} \mathrm{C}$. Which is much too small compared to the minimum theoretical $9.0 \%$. This observation indicates that some Si-related species, such as non-hydrolyzed TEOS or silanol groups, evaporated during sonication or during the heat treatment. In the first case, the drying process should not yet be complete when the sample weight attained the limit value $\mathrm{X}_{\text {eq }}$ for $\mathrm{T}_{\text {OVEN }}=70$ and $83{ }^{\circ} \mathrm{C}$. This is unlikely because a long time elapsed without weight variation until the treatment was interrupted. In the second case, hydrolysis and polycondensation reactions may be occurring during the heat treatment with possibility of changes in the gel structure.

The drying rates, $\mathrm{dX} / \mathrm{dt}$, in $\min ^{-1}$ units, were determined from the slopes of the curves of the Fig. 2. Following a typical procedure to characterize the drying periods ${ }^{12}$, Fig. 4 shows the drying rate curves as a function of the percentage of the sample weight $(\mathrm{X})$. The drying rate increases strongly with the temperature and decreases continuously as the sample loses weight, until practically no changes of weight can be detected. After a fairly linear drop of the drying rate with $\mathrm{X}$, whose extension was dependent on the temperature, the samples exhibited little change in regime of the drying process. This can be inferred from the more accelerated diminution of the drying rates at $\mathrm{X} \sim 80 \%$ for

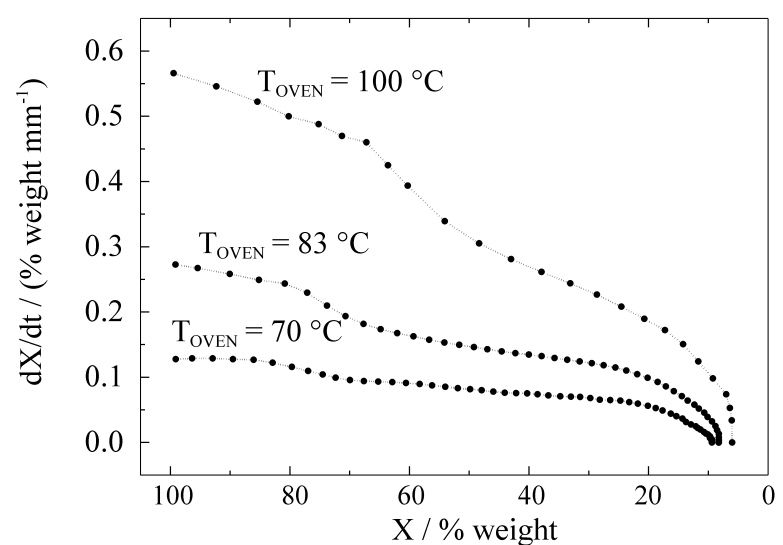

Figure 4. Drying rate as a function of the instantaneous weight of the sample placed into the oven at the temperature TOVEN

$\mathrm{T}_{\text {OVEN }}=70{ }^{\circ} \mathrm{C}$ sample, $\mathrm{X} \sim 75 \%$ for $\mathrm{T}_{\text {OVen }}=83{ }^{\circ} \mathrm{C}$, and $\mathrm{X} \sim 65 \%$ for Toven $=100{ }^{\circ} \mathrm{C}$. This deceleration in the drying rate is more apparent at high temperatures and should be associated to variations in the composition of the alcohol and other volatile non-reacted Si-related compounds present in the liquid phase of the gel. The evaporation of volatile Si-related compounds is favoured at high temperatures since the weight loss has already attained $\sim 35 \%(\mathrm{X} \sim 65 \%)$ at $\mathrm{T}_{\text {OVEN }}=100{ }^{\circ} \mathrm{C}$, which is even greater than the alcohol content, when the deceleration in the drying rate becomes apparent.

We have estimated, from the theoretical $\mathrm{X}_{\mathrm{eq}}$, that these wet gel samples are almost $98 \%$ volume liquid phase. Hence the bulk density is close to the density of the liquid phase. In this case, the volume shrinkage of the gel is equal to the volume of liquid that evaporates while the liquid/vapour meniscus is kept flat at the external surface of the body and the solid network collapses into the liquid by capillary forces, as pointed out by Scherer ${ }^{5}$. Assuming an isotropic linear shrinkage, we have

$$
\frac{\mathrm{dS}}{\mathrm{S}}=\frac{2}{3} \frac{\mathrm{dV}}{\mathrm{V}}
$$

where $\mathrm{S}$ and $\mathrm{V}$ are instantaneous external surface area and bulk volume of the body, respectively. Integrating (1) from the initial wet gel conditions $\left(S_{o}, V_{o}\right)$, we obtain

$$
\mathrm{S}=\mathrm{S}_{0}\left(\frac{\mathrm{V}}{\mathrm{V}_{0}}\right)^{2 / 3} \alpha \mathrm{V}^{2 / 3} \alpha \mathrm{M}^{2 / 3} \alpha \mathrm{X}^{2 / 3}
$$

where $\mathrm{M}$ is the instantaneous weight of the gel. Equation (2) should be observed during the CRP, while the volume shrinkage is equal to volume of liquid that evaporates. The proportionality between $\mathrm{V}$ and $\mathrm{M}$ (or $\mathrm{X}$ ) is valid since the bulk density is practically constant, even if some Si-related species evaporate, except when the CRP has finished. According to Eq. (2), the quantity $(\mathrm{dX} / \mathrm{dt}) / \mathrm{X}^{2 / 3}$ is proportional to the drying rates, normalized by the instantaneous surface area. Figure 5 shows $(\mathrm{dX} / \mathrm{dt}) / \mathrm{X}^{2 / 3} v s$. 


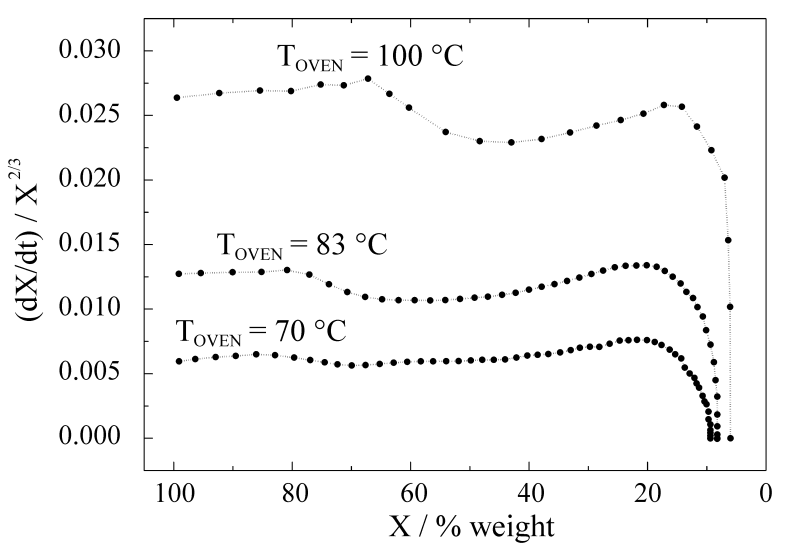

Figure 5. Drying rates normalised with respect to the function $X^{2 / 3}$.

$\mathrm{X}$ plots. The normalised drying rate in Fig. 5 is practically constant at the beginning of the drying process until about $\mathrm{X} \sim 80 \%$ for Toven $=70{ }^{\circ} \mathrm{C}, \mathrm{X} \sim 75 \%$ for TOVen $=83{ }^{\circ} \mathrm{C}$ and $\mathrm{X} \sim 65 \%$ for $\mathrm{T}_{\text {OVEN }}=100{ }^{\circ} \mathrm{C}$. Next, the drying rate drops to a minor but yet constant value until the gel weight achieves approximately $40 \%$ or $30 \%$ of its initial weight. The regime changes of the drying rate, namely: at $\mathrm{X} \sim 80 \%$ for $\mathrm{T}_{\text {OVEN }}=70{ }^{\circ} \mathrm{C}, \mathrm{X} \sim 75 \%$ for $\mathrm{T}_{\text {OVEN }}=83{ }^{\circ} \mathrm{C}$ and $\mathrm{X} \sim 65 \%$ for TOVEN $=100^{\circ} \mathrm{C}$, which we have associated to the ending of the alcohol content and others volatile non-reacted Si-related compounds present in the liquid phase of the gel, are more apparent in Fig. 5 than in Fig. 4. The late increase in the normalised drying rate which occurs after $X \sim 30 \%$ or $40 \%$, according to the Fig. 5, can be explained by the

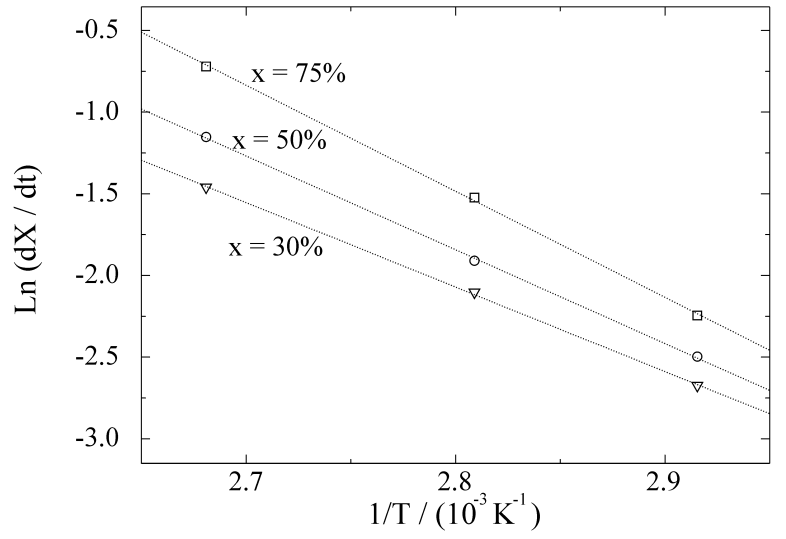

Figure 6. Drying rates fitting an Arrhenius equation for different constant values of the weight of the samples.

Table 1. Apparent activation energy of the drying process as a function of the weight of the samples.

\begin{tabular}{lc}
\hline $\mathrm{X}(\%$ weight $)$ & $\Delta \mathrm{E}(\mathrm{kJ} / \mathrm{mol})$ \\
\hline 75 & 53.9 \\
50 & 47.7 \\
30 & 43.0 \\
\hline
\end{tabular}

normalisation function $\mathrm{X}^{2 / 3}$ which should begin to departure from a true measurement of the external surface area when the shrinkage of gel is ceasing, the CPR regime is finishing and the first falling rate period is starting. In addition, cracking is favoured in the first falling rate period when the pores start to empty, mainly under high temperature. The appearing of cracks increases the evaporation surface area, increasing the evaporation rate, what does not permit to unequivocally study the falling rate periods with this set experimental data. As a matter of fact, the sample treated at TOVEN $=70{ }^{\circ} \mathrm{C}$ remained apparently monolithic, while that at TOVEN $=83{ }^{\circ} \mathrm{C}$ was found fractured, and at $\mathrm{T}_{\text {OVEN }}=100^{\circ} \mathrm{C}$ was found broken.

The drying rate as a function of the sample temperature, as measured at fixed values of the sample weight $(\mathrm{X}=$ constant), namely $X=75 \%, X=50 \%$ and $X=30 \%$, is plotted in Fig. 6 (an Arrhenius type plot). Table 1 shows the activation energy $(\Delta \mathrm{E})$, obtained from the slope of the linear regression of the $\ln (\mathrm{dX} / \mathrm{dt}) v s$. $(1 / \mathrm{T})$ data fitting the Arrhenius equation for each $\mathrm{X}=$ constant. The activation energy decreases with $X$ and tends to the value $43 \mathrm{~kJ} / \mathrm{mol}$ at $X=30 \%$, the sample weight in which we suspect the CPR has ended. $43 \mathrm{~kJ} / \mathrm{mol}$ is close to the heat of evaporation of the water. The apparent increase of the activation energy for high $\mathrm{X}$ values could be associated to the preferential evaporation of the volatile compounds present in the liquid phase which would shift upward the experimental $\mathrm{dX} / \mathrm{dt}$ at the high temperature side of the Fig. 6.

The set of the experimental results is compatible with the model in which the greatest changes in volume and weight of the gel, with consequent changes in the structure of the gel, is controlled by evaporation from a flat liquidvapour interface at the surface of the body and contraction of the gel by capillary forces. Polycondensation must occur during the heat treatment, and associated structural changes are induced by siloxane bond formation, which partially account for the irreversible shrinkage. The employed thermogravimetric method does not permit to unequivocally follow the small and slow final loss of weight associated to the falling rate periods.

\section{Conclusion}

The greatest changes in volume and weight of this set of high water content TEOS-derived gels are compatible with a mechanism controlled by evaporation from a flat liquid-vapour interface at the surface of the body and contraction of the gel by capillary forces. Structural changes must occur during the heat treatment induced by siloxane bond formation (polycondensation) which partially account for the irreversible shrinkage of the gels. The thermogravimetric method employed does not permit to unequivocally follow the small and slow final loss of weight associated to the falling rate periods. 


\section{Acknowledgments}

This work was supported by FAPESP (Brazil).

\section{References}

1.Hench, L.L.; Wilson, M.J.R. J. Non-Cryst. Solids, v. 121, p. 234-243, 1990.

2. Ge, M.; Yang, H.; Jiang, Z.; Wang, Y.; Zhang, F. J. Non-Cryst. Solids, v. 147-148, p. 565-568, 1992.

3. Santos, D.I.; Aegerter, M.A.; Craievich, A. Cerâmica, v. 35, p. 13-17, 1989.

4. Pajonk, G.M.; Repellin-Lacroix, M.; Abouarnadasse, S.; Chaouki, J.; Klvana, D. J. Non-Cryst. Solids, v. 121, p. 66-67, 1990.

5. Scherer, G.W. J. Non-Cryst. Solids, v. 147-148, p. 363-374, 1992.
6. Scherer, G.W. J. Non-Cryst. Solids, v. 100, p. 77-92, 1988.

7. Yasumori, A.; Kawazoe, H.; Yamane, M. J. NonCryst. Solids, v. 100, p. 215-219, 1988.

8. Kawaguchi, T.; Iura, J.; Taneda, N.; Hishikura, H.; Kokubu, Y. J. Non-Cryst. Solids, v. 82, p. 50, 1986.

9. Donatti, D.A.; Vollet, D.R. J. Non-Cryst. Solids, v. 208, p. 99-104, 1996.

10. Donatti, D.A.; Vollet, D.R. J. Sol-Gel Sci. Tech., v. 4, p. 99-104, 1995.

11. Dahmouche, K. PhD Thesis, Lyon University, 1993.

12. Strumillo, C.; Kudra, T. Drying: Principles, Applications and Design, Gordon and Breach Sci. Publishers, N. York, p. 71, 1986. 